\title{
Correction to: Photosynthesis in Algae: Biochemical and Physiological Mechanisms
}

\author{
Anthony W. D. Larkum, Arthur R. Grossman, and John A. Raven
}

\section{Correction to:}

A. W. D. Larkum et al. (eds.), Photosynthesis in Algae:

Biochemical and Physiological Mechanisms, Advances in Photosynthesis and Respiration 45, https://doi.org/10.1007/978-3-030-33397-3

This book was inadvertently published with a spell error in the name of the editor as Arthur R. Grossmann. This has now been corrected as Arthur R. Grossman on the Cover of the book and on the front matter pages iv, $\mathrm{v}$, and xxvi. 